\title{
ON THE CONVERGENCE OF ALUTHGE SEQUENCE
}

\author{
Huajun HuAng AND Tin-Yau TAM
}

Abstract. For $0<\lambda<1$, the $\lambda$-Aluthge sequence $\left\{\Delta_{\lambda}^{m}(X)\right\}_{m \in \mathbb{N}}$ converges if the nonzero eigenvalues of $X \in \mathbb{C}_{n \times n}$ have distinct moduli, where $\Delta_{\lambda}(X):=P^{\lambda} U P^{1-\lambda}$ if $X=U P$ is a polar decomposition of $X$.

Mathematics subject classification (2000): 15A23, 15A45.

Key words and phrases: $\lambda$-Aluthge transform, polar decomposition, normal matrix.

\section{REFERENCES}

[1] A. Aluthge, On $p$-hyponormal operators for $0<p<1$, Integral Equations Operator Theory, 13 (1990), 307-315.

[2] A. Aluthge, Some generalized theorems on p-hyponormal operators, Integral Equations Operator Theory, 24 (1996), 497-501.

[3] T. ANDO, Aluthge transforms and the convex hull of the eigenvalues of a matrix, Linear Multilinear Algebra, 52 (2004), 281-292.

[4] T. ANDO AND T. YAMAZAKI, The iterated Aluthge transforms of a 2-by-2 matrix converge, Linear Algebra Appl., 375 (2003), 299-309.

[5] J. AnteZAna, P. Massey And D. StojanofF, $\lambda$-Aluthge transforms and Schatten ideals, Linear Algebra Appl., 405 (2005) 177-199.

[6] R. BHATIA AND F. KiTtANEH, Some inequalities for norms of commutators, SIAM J. Matrix Anal. Appl., 18 (1997) 258-263.

[7] М. СНO, I. B. Jung AND W. Y. LEE, On Aluthge transform of p-hyponormal operators, Integral Equations Operator Theory, 53 (2005), 321-329.

[8] C. FoIAŞ, I. B. Jung, E. KO AND C. PEARCY, Complete contractivity of maps associated with the Aluthge and Duggal transforms, Pacific J. Math., 209 (2003), 249-259.

[9] P. R. Halmos, A Hilbert Space Problem Book, Springer-Verlag, New York, 1974.

[10] S. Helgason, Differential Geometry, Lie Groups, and Symmetric Spaces, Academic Press, New York, 1978.

[11] I. B. JUnG, E. Ko AND C. PEARCY, Aluthge transforms of operators, Integral Equations Operator Theory, 37 (2000), 437-448.

[12] I. B. Jung, E. Ko AND C. PEARCY, Spectral pictures of Aluthge transforms of operators, Integral Equations Operator Theory, 40 (2001), 52-60.

[13] I. B. Jung, E. Ko AND C. PEARCY, The iterated Aluthge transform of an operator, Integral Equations Operator Theory, 45 (2003), 375-387.

[14] K. OKUBO, On weakly unitarily invariant norm and the Aluthge transformation, Linear Algebra Appl., 371 (2003), 369-375.

[15] A. L. ONISHCHIK AND E. B. VINBERG, Lie groups and algebraic groups, Springer-Verlag, Berlin, 1990.

[16] T. YAMAZAKI, An expression of spectral radius via Aluthge transformation, Proc. Amer. Math. Soc., 130 (2002), 1131-1137.

[17] T. YAMAZAKI, On numerical range of the Aluthge transformation, Linear Algebra Appl., 341 (2002) $111-117$. 